\title{
STATUS OF BRUCELLOSIS IN DAIRY CATTLE OF KAPILVASTU AND BHAKTAPUR DISTRICTS OF NEPAL
}

\author{
B. Ghimire ${ }^{1}$, S. Thapa Chhetri ${ }^{2}$ and D. R. Khanal ${ }^{3^{*}}$ \\ ${ }^{1}$ Asia Network for Sustainable Agriculture Bioresources (ANSAB), Kathmandu \\ ${ }^{2}$ Agriculture and Forestry University, Rampur, Chitwan \\ ${ }^{3}$ Animal Health Research Division, Nepal Agricultural Research Council, Lalitpur \\ (*email: drkhana17@gmail.com)
}

\begin{abstract}
Brucellosis is a zoonotic disease that causes abortion in dairy cattle. To find out its status, serological tests were conducted, during June-July 2013, in 48 sera samples from dairy cattle (23 from Kapilvastu and 25 from Bhaktapur districts) having the recent history of abortion. Out of 48 samples 6 (12.5\%) were positive on Rose Bengal Plate Test. Among 6 positive samples, 2 (8.69\%) were from Kapilvastu and 4 (16\%) from Bhakhtapur. Considering the positive cases of brucellosis in the dairy pocket areas and its threat of transmission to other animals and human, a suitable preventive and control measures including the regular test and segregation of sero-positive animals, effective quarantine, legislative measures and awareness programs for farmers, veterinarian, technicians and stakeholders are recommended.
\end{abstract}

Keywords: abortion, brucella, cattle, rose bengal plate test, zoonosis

\section{INTRODUCTION}

Brucellosis is one of the most widespread bacterial zoonotic diseases of cattle, buffalo, swine, goats, sheep, dogs and human, resulting into tremendous economic losses in endemic regions. In human, it causes Malta or Mediterranean fever (Godfroid et al., 2005). It is caused by gramnegative coccobacilli of the genus Brucella that contains a group of very closely related bacteria. The first member of the group, Brucella melitensis, affects primarily sheep and goats. The second member of the group, Brucella abortus, affects primarily cattle, the third member of the group, Brucella suis, affects primarily pigs, the fourth member of the group, Brucella ovis, affects primarily rams and ewes, the fifth member of the group, Brucella neotomae, affects primarily the desert wood rats, and the sixth member of the group, Brucella canis, affects primarily male dogs and bitches (Corbel and Macmillan, 1998). Cattle infected with B. melitensis poses a public health problem. B. abotus is communicable from cattle to sheep or sheep to sheep or sheep to cattle (Chakrabarti, 2007).

Brucellosis has both public health and economic significance in most developing countries. The disease is transferred from meat, milk and other contaminated materials. Epidemiological information could be important tool in control and eradication. Establishing the epidemiology of the disease could be an important source of information for farmers, students, future researchers, control strategy and other persons as well.There have been little studied on abortive diseases in dairy cattle in Nepal. This study was therefore, aimed at assessing the status of brucellosis in dairy cattle of selected pocket areas of Kapilvastu and Bhaktapur districts. 


\section{MATERIALS AND METHODS}

\section{Study areas}

Kapilvastu and Bhaktapur districts were selected as the study area where the large numbers of abortion occurred in dairy cattle. The selected areas have high potential for milk production in recent year. Nowadays, the numbers of cross breeds are increasingly used for large amount of milk production in this area. Abortion causes huge economic losses in that area and small dairy farmers are suffering from this problem. The blood samples were collected from aborted cattle at Motipur, Kopawa, Bhalwad, Banganga, Hathausa, Budhi, and Gajehada of Kapilvastu district and Balkot, Dadhikot, Jhaukhel, Sirutar and Bageswori of Bhaktapur district.

\section{Blood sampling}

A total of 48 blood samples (23 from different VDCs of Kapilvastu district and 25 from different VDCs of Bhaktapur) were collected from cattle with recent history of abortion. About $5 \mathrm{ml}$ of blood was collected aseptically from the jugular vein and serum samples were extracted in serum vials and stored in refrigerator at $4^{\circ} \mathrm{C}$ until tests.

\section{Rose Bengal plate test (RBPT)}

Laboratory examinations of samples were conducted at Animal Health Research Division, NARC, Khumaltar, Lalitpur. The RBPT test was performed according to information provided by OIE guidelines (2009). Briefly, the serum samples and antigen were placed to room temperature (22 \pm $4^{\circ} \mathrm{C}$ ); only sufficient antigen for the day's tests was removed from the refrigerator. $30 \mu \mathrm{l}$ of each serum sample was placed on a clean grease free glass slide. The antigen bottle was well shaken, gently, and placed equal volume of antigen near each serum spot. Immediately after the last drop of antigen has been added to the plate, the serum and antigen were mixed thoroughly (using a clean glass or plastic rod for each test) to produce a circular or oval zone approximately $2 \mathrm{~cm}$ in diameter. The mixture was agitated gently for 4 minutes at ambient temperature manually. It was then read for agglutination immediately after the 4-minute period was completed. Any visible agglutination was considered to be positive and none agglutinated mixture was considered to be negative.

\section{Questionnaire survey}

The questionnaires were designed to retrieve information from each farmer on the usual main risk factors, such as the introduction of infected animals into the herd, the level of management system in the farm and the exposure of the herd to an infectious disease. It is also concerned with the general management of the farm, recording system and health problems.

\section{Data Analysis}

The data were analyzed to determine the percentage of positive cases for brucellosis.

\section{RESULTS}

\section{Management status and animal details}

Questionnaire survey based management status of animals in the study area is shown in Table 1. Survey revealed that $(85 \%)$ of the farmers of both Kapilvastu and Bhaktapur districts adopted semi intensive system while remaining (15\%) practiced intensive farming system. Furthermore, it was understood that $(80 \%)$ of farmers (households) used artificial insemination for breeding purpose 
whereas only (20\%) used bull for breeding their dairy cattle. Regarding the cases of abortion and repeat breeding in dairy cattle, $25 \%$ of household reported the cases of abortion in first trimester, $15 \%$ in second trimester, $8 \%$ in third trimester and $52 \%$ of household had no history of abortion in their dairy cattle. Similarly, $47 \%$ of household had experienced the cases of repeat breeding in their dairy cattle.

Table 1:Status of animal management in Kapilvastu and Bhaktapur districts

\section{Activities}

Animal details

1.Breeding of animal

a. Artificial Insemination

b. Natural service

\section{History of abortion}

a. First trimester

b. Second trimester

c. Third trimester

d. No history of abortion

3.History of repeat breeding

4. Farming system

a. Intensive

b. Semi intensive

\section{Households}

Number

Percentage (\%)

$80 \quad 80 \%$

$20 \quad 20 \%$

$25 \quad 25 \%$

$15 \quad 15 \%$

$8 \quad 8 \%$

$52-52 \%$

$47 \quad 47 \%$

$15 \quad 15 \%$

$85 \quad 85 \%$

\section{Rose Bengal Plate Test (RBPT) result}

Out of 48 samples screened by the RBPT six (12.5\%) were found positive of which 4 were from Bhaktapur and 2 were from Kapilvastu district (Fig. 1).

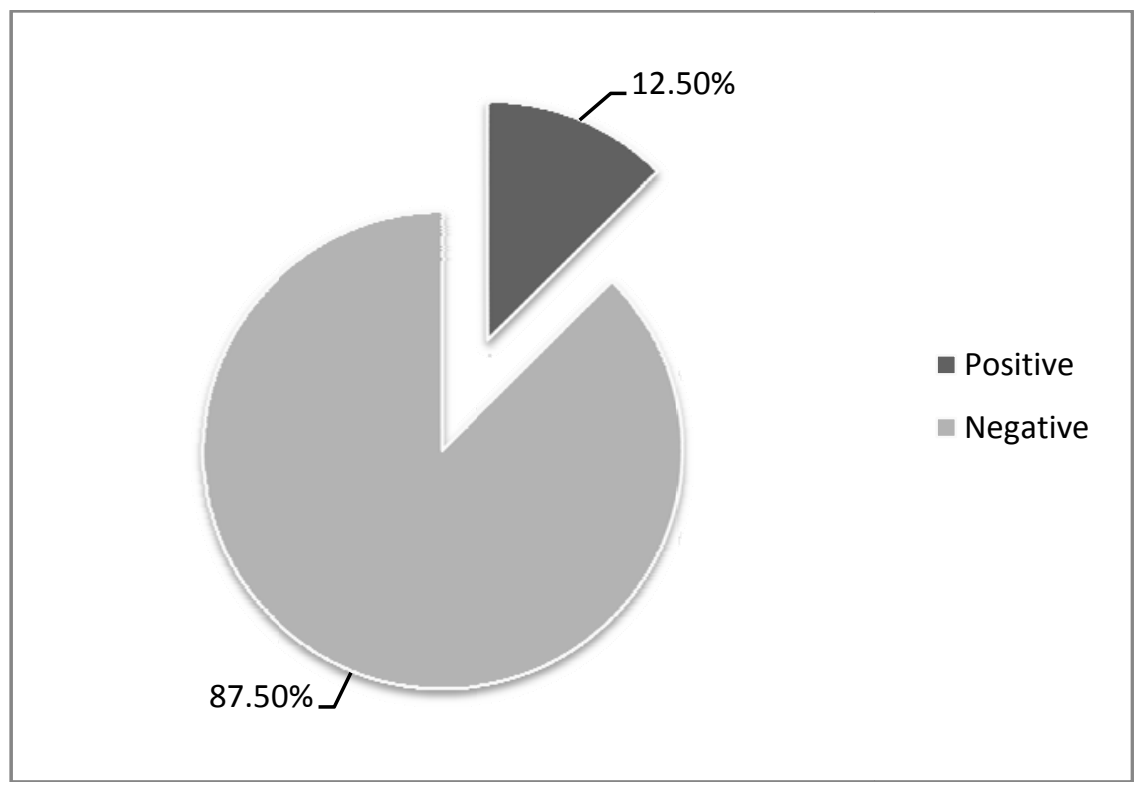

Fig.1: Showing result of Rose Bengal test for brucellosis 


\section{District wise status of brucellosis}

Out of six positive samples four were from Bhaktapur and two were from Kapilvastu district (Fig. 2).

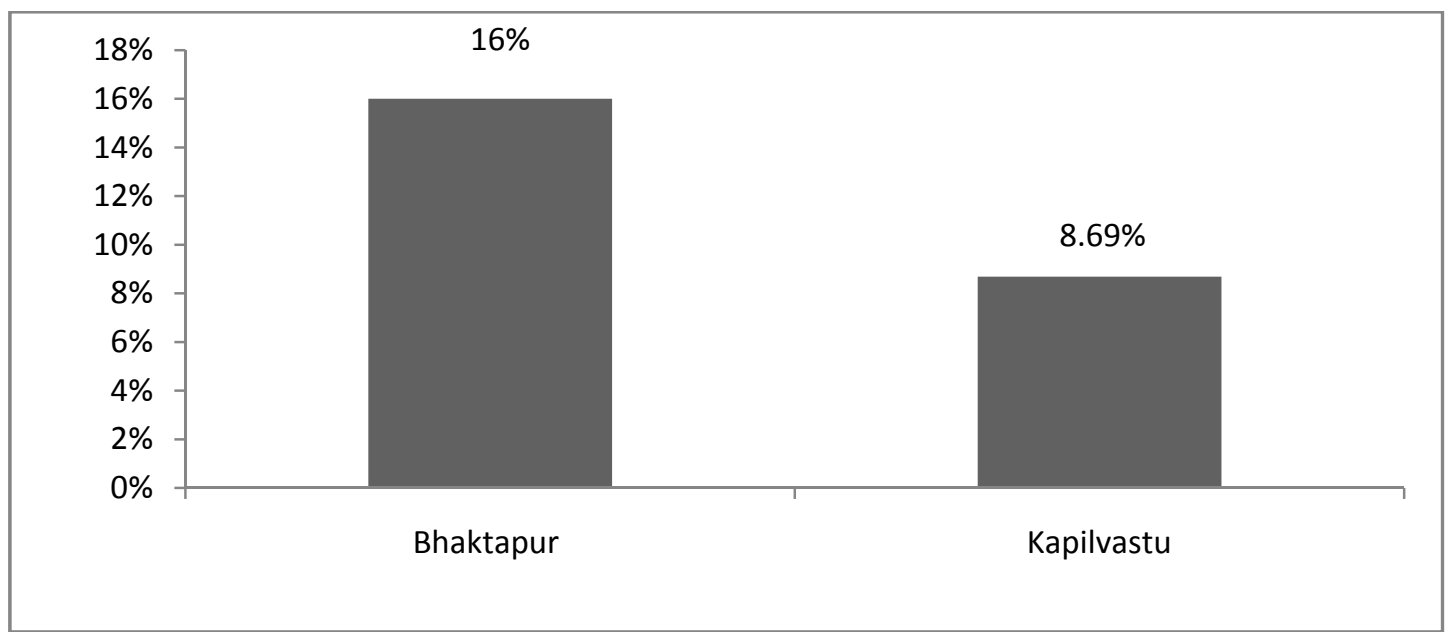

Fig. 2: District wise prevalence of brucellosis

\section{VDC wise status of brucellosis in Bhakhtapur district}

Out of four positive samples of Bhakhtapur district two samples Jhaukhel were positive for brucellosis and one sample each was found positive in Balkot and Sirutar VDC no positive samples were found in Dadhikot and Bageswori (Fig. 3).

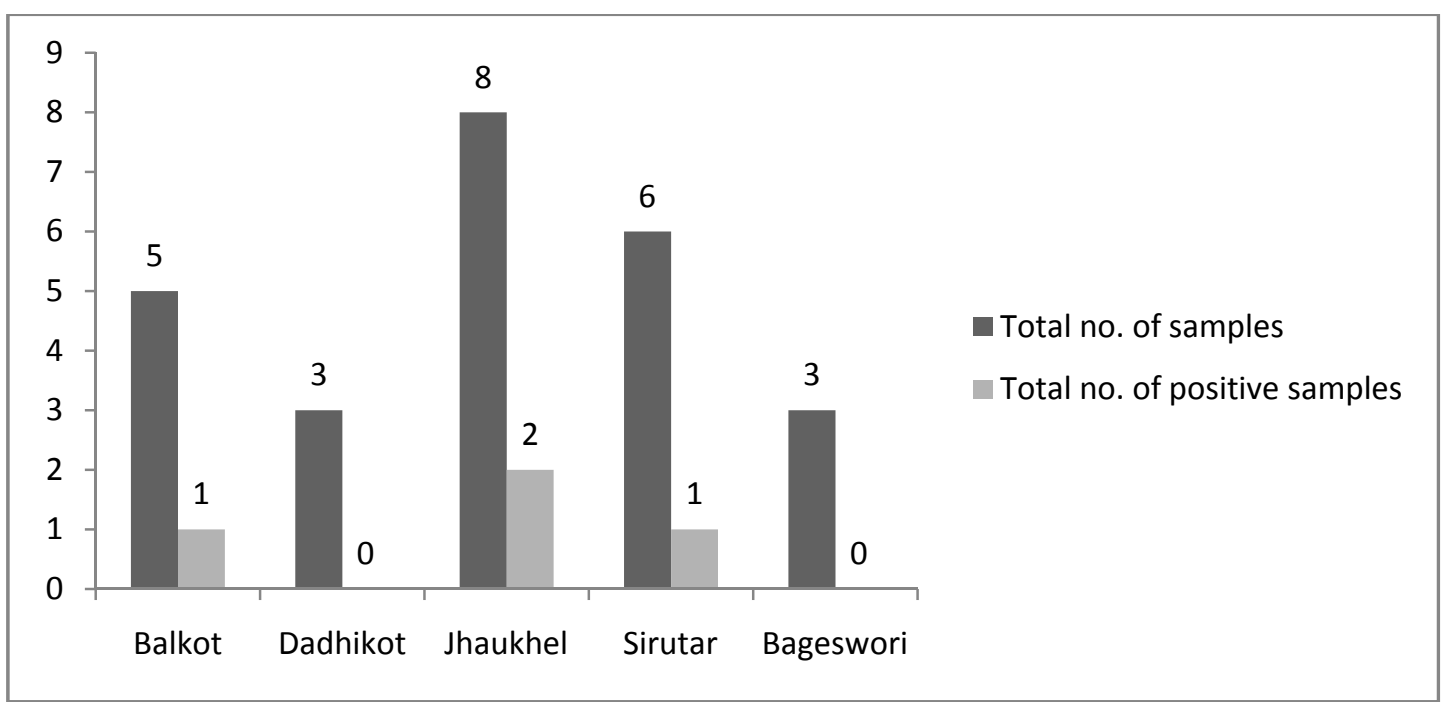

Fig. 3: VDC wise prevalence of brucellosis in Bhakhtapur district

\section{VDC wise status of brucellosis in Kapilvastu district}

Out of two positive samples of Kapilvastu district each positive case was from Motipur and Banganga VDC (Fig. 4). 


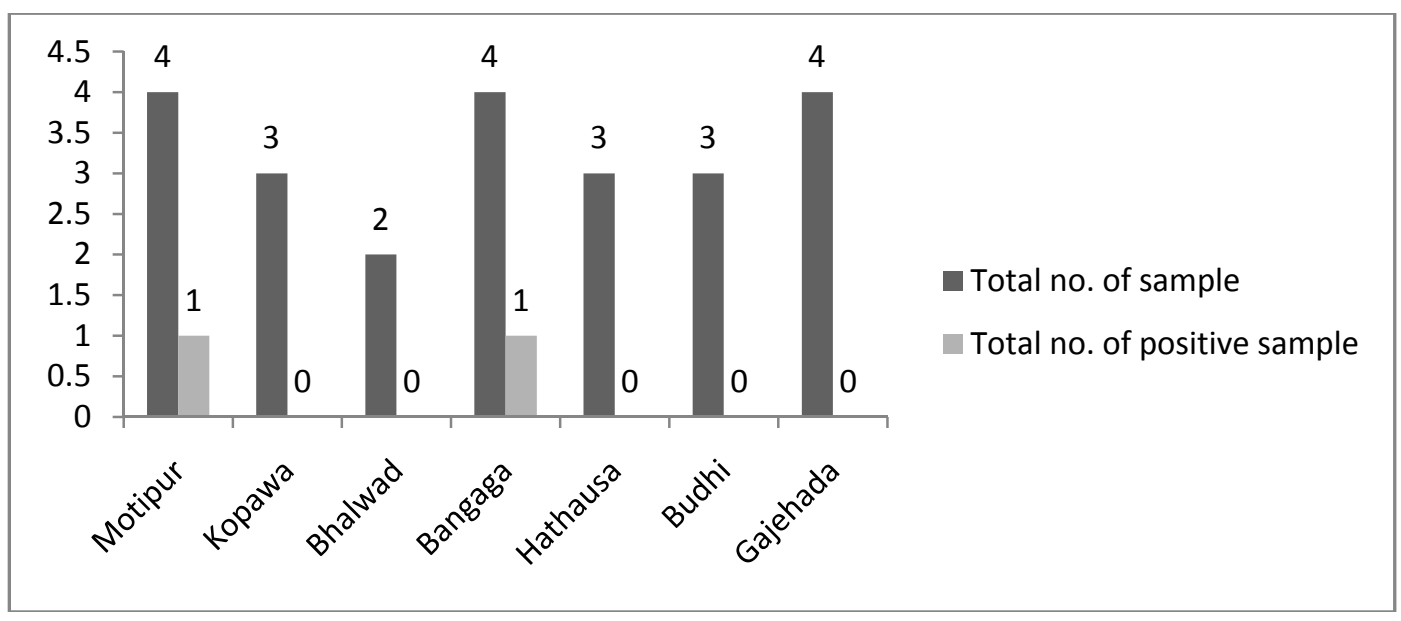

Fig. 4: VDC wise prevalence of brucellosis in Kapilvastu district

\section{Age wise status of brucellosis in dairy cattle}

Out of six positive samples two were from 0-4 year's age group and rest were from above the four years age group (Fig. 5).

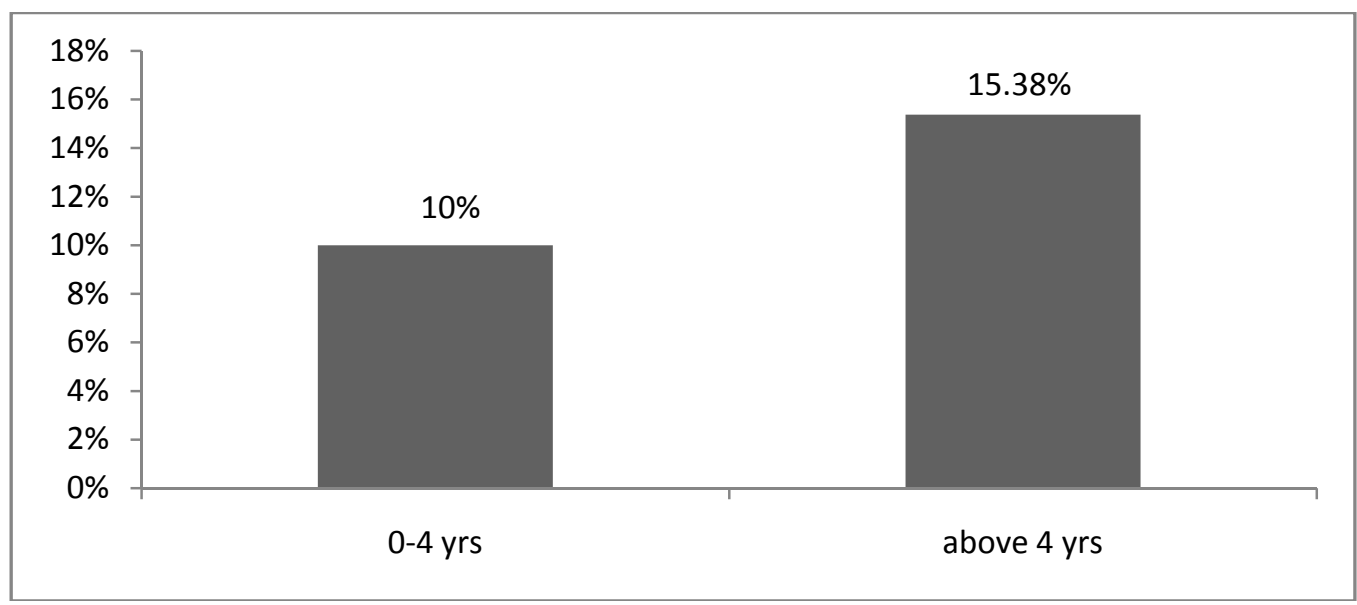

Fig. 5: Age wise prevalence of brucellosis

\section{DISCUSSION}

The husbandry system adopted in Bhaktapur and Kapilvastu are mostly traditional sedentary without scientific housing system. There is close contact between human and animal during milking, feeding, grazing, care during parturition, which may result in the transmission of zoonotic diseases. The present finding is like the result obtained by Pandeya (2013) in different animal species of Kailali district. Lack of quality semen for AI, use of the unscreened bull for natural service, improper handling of aborted materials, improper import of bulls and lack of awareness on brucellosis among the farmers and the public are causes for the transmission.

Earlier Pyakurel and Mishra (1977) found 22.64\% positive cases of brucellosis in buffalo, which is quite higher than the present finding. Pyakurel and Mishra (1977) tested for the prevalence of 
brucellosis in cattle of Kathmandu and found (17.47\%) were positive. Present finding is quite like the finding of Pyakurel and Mishra (1977).

The analysis carried out by DHS (2003) indicated that in Nepal around (2-3\%) of the cattle and buffalo are sero-positive, which is quite lesser than this finding. This contrast result might be due to less number of animals and the aborted dairy cattle whose main cause might be brucellosis for abortion. Dhakal et al., (2005) carried out the serological study in 35 slaughtered buffaloes in Chitwan and (2.86\%) of the buffaloes were found to be positive for brucellosis. Mishra (2008) studied the sero-prevalence of brucellosis in buffaloes of Bhaktapur district and found (15\%) to be positive, which is quite like this finding. This might be due to the reason of rearing of cattle and buffalo in the same farm of those areas where there is chance of transmission of the disease from infected to the healthy ones.

\section{CONCLUSION}

Serological screening of dairy cattle with the history of abortion in Kapilvastu and Bhaktapur districts has indicated $12.5 \%$ of cattle ( 6 out of 48 ) positive for brucellosis, the latter showing more positive cattle $(16 \%)$ than Kapilvastu $(8.69 \%)$. Since dairy cattle are raised near with human population, direct contact with aborted materials and placenta in absence of protective gears shall increase the likelihood of contracting brucellosis in humans in affected districts. Thus, the status of brucellosis in human is another facet to be studied.

\section{ACKNOWLEDGEMENT}

The authors expresses their sincere thanks to Dr.Vijay Chandra Jha for providing Brucella antigen without which my research could not be completed and to Mrs. Durga Karki, Senior Technical Officer of NARC who helped me to perform laboratory work.

\section{REFERENCES}

Chakrabarti, A. (2007). A Text Book of Preventive Medicine. Seventh Edition, Kalyani Publishers, New Delhi, 317-324.

Corbel, M.J. and Macmillan, A.P. (1998). Brucellosis. Bacterial Infections, 3: 819-820.

Dhakal, I.P., Jost, C., Pakhrin, B. and Jhosi, D.D. (2005). Training on livestock and Poultry Derived Food Safety and Hygiene in Four Communities in Chitwan District. The Blue Cross Annual Bulletin, NVSA, 7: 8-14.

Godfroid, J., Cloeckaert, A., Fretin, D. and Letsson, J.J. (2005). From the discovery of the Malta fever's agent to the discovery of marine mammal reservoir brucellosis has continuously been a re-emerging zoonosis veterinary research, 36: 313-326.

Mishra, Y. (2008). Prevalence of brucellosis in buffaloes at different site of Bhaktapur district. B.V.Sc. \& AH mini thesis report. HICAST, PU, Nepal.

Pandeya, Y.R. (2013). Sero-prevalence of brucellosis in different animal species of Kailali District. B. V. Sc. \& AH. Mini thesis Report. IAAS, TU. Nepal.

Pyakurel, S. and Mishra, U. (1977). Sero-Epidemiological Evidence of Animal Brucellosis in Nepal, Bull. Veterinary Science \& Animal Husbandry, Nepal, 6: 1-6. 